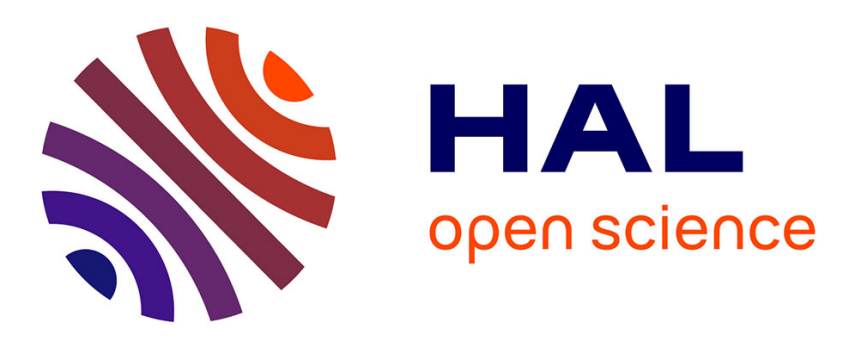

\title{
C ion-implanted TiO2 thin film for photocatalytic applications
}

\author{
G. Impellizzeri, V. Scuderi, L. Romano, E. Napolitani, R. Sanz, Robert \\ Carles, V. Privitera
}

\section{- To cite this version:}

G. Impellizzeri, V. Scuderi, L. Romano, E. Napolitani, R. Sanz, et al.. C ion-implanted TiO2 thin film for photocatalytic applications. Journal of Applied Physics, 2015, 117 (10), pp.105308 - 173507. 10.1063/1.4915111 . hal-01763598

\section{HAL Id: hal-01763598 \\ https://hal.science/hal-01763598}

Submitted on 11 Apr 2018

HAL is a multi-disciplinary open access archive for the deposit and dissemination of scientific research documents, whether they are published or not. The documents may come from teaching and research institutions in France or abroad, or from public or private research centers.
L'archive ouverte pluridisciplinaire HAL, est destinée au dépôt et à la diffusion de documents scientifiques de niveau recherche, publiés ou non, émanant des établissements d'enseignement et de recherche français ou étrangers, des laboratoires publics ou privés. 


\section{C ion-implanted $\mathrm{TiO}_{2}$ thin film for photocatalytic applications}

G. Impellizzeri, V. Scuderi, L. Romano, E. Napolitani, R. Sanz, R. Carles, and V. Privitera

Citation: Journal of Applied Physics 117, 105308 (2015); doi: 10.1063/1.4915111

View online: https://doi.org/10.1063/1.4915111

View Table of Contents: http://aip.scitation.org/toc/jap/117/10

Published by the American Institute of Physics

\section{Articles you may be interested in}

Fe ion-implanted $\mathrm{TiO}_{2}$ thin film for efficient visible-light photocatalysis

Journal of Applied Physics 116, 173507 (2014); 10.1063/1.4901208

Aluminum multicharged ion generation from femtosecond laser plasma

Journal of Applied Physics 121, 185901 (2017); 10.1063/1.4983008

Multicharged carbon ion generation from laser plasma

Review of Scientific Instruments 87, 113304 (2016); 10.1063/1.4966987

Controlled formation of anatase and rutile $\mathrm{TiO}_{2}$ thin films by reactive magnetron sputtering AIP Advances 5, 097168 (2015); 10.1063/1.4931925

Wafer-scale synthesis of multi-layer graphene by high-temperature carbon ion implantation Applied Physics Letters 107, 033104 (2015); 10.1063/1.4926605

Structural defects induced by $\mathrm{Fe}$-ion implantation in $\mathrm{TiO}_{2}$ Journal of Applied Physics 115, 053711 (2014); 10.1063/1.4864748

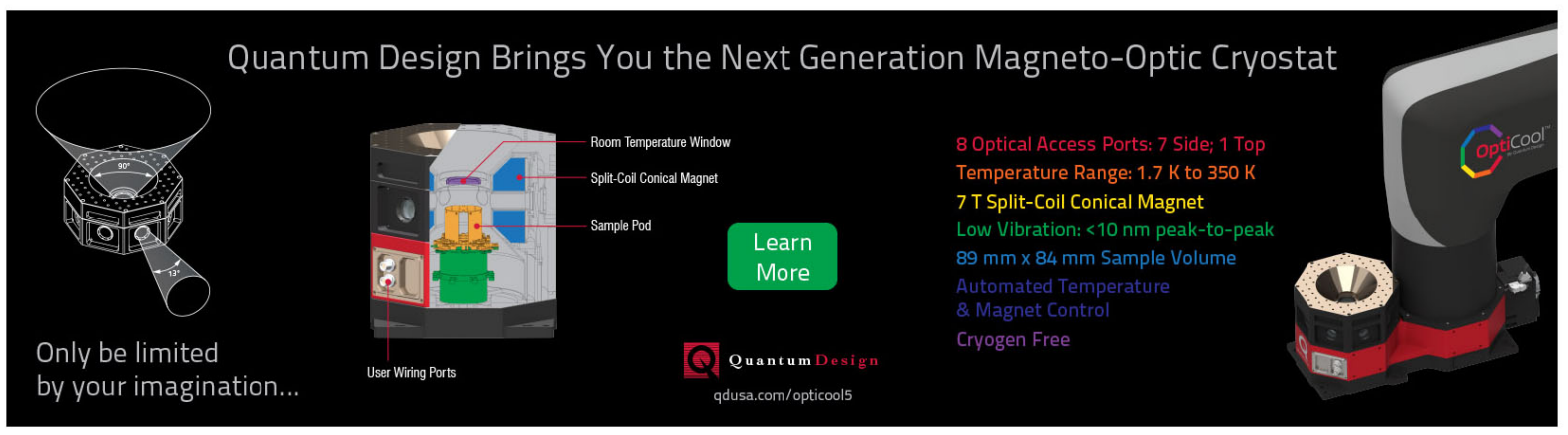




\title{
C ion-implanted $\mathrm{TiO}_{2}$ thin film for photocatalytic applications
}

\author{
G. Impellizzeri, ${ }^{1, a)}$ V. Scuderi, ${ }^{1}$ L. Romano, ${ }^{1,2}$ E. Napolitani, ${ }^{1,3}$ R. Sanz, ${ }^{1}$ R. Carles, ${ }^{4}$ \\ and V. Privitera ${ }^{1}$ \\ ${ }^{1}$ CNR-IMM MATIS, Via S. Sofia 64, 95123 Catania, Italy \\ ${ }^{2}$ Dipartimento di Fisica e Astronomia, Università di Catania, Via S. Sofia 64, 95123 Catania, Italy \\ ${ }^{3}$ Dipartimento di Fisica ed Astronomia, Università di Padova, Via Marzolo 8, 35131 Padova, Italy \\ ${ }^{4}$ Université de Toulouse, CEMES CNRS, 29 rue Marvig, BP 94347, 31055 Toulouse Cedex 4, France
}

(Received 26 January 2015; accepted 4 March 2015; published online 13 March 2015)

Third-generation $\mathrm{TiO}_{2}$ photocatalysts were prepared by implantation of $\mathrm{C}^{+}$ions into $110 \mathrm{~nm}$ thick $\mathrm{TiO}_{2}$ films. An accurate structural investigation was performed by Rutherford backscattering spectrometry, secondary ion mass spectrometry, X-ray diffraction, Raman-luminescence spectroscopy, and UV/VIS optical characterization. The $\mathrm{C}$ doping locally modified the $\mathrm{TiO}_{2}$ pure films, lowering the band-gap energy from $3.3 \mathrm{eV}$ to a value of $1.8 \mathrm{eV}$, making the material sensitive to visible light. The synthesized materials are photocatalytically active in the degradation of organic compounds in water under both UV and visible light irradiation, without the help of any additional thermal treatment. These results increase the understanding of the C-doped titanium dioxide, helpful for future environmental applications. (C) 2015 AIP Publishing LLC.

[http://dx.doi.org/10.1063/1.4915111]

\section{INTRODUCTION}

In the recent years, a great effort has been devoted to developing heterogeneous photocatalysts for environmental applications, such as water purification and disinfection, air purification, and hydrogen production from water splitting. ${ }^{1-4}$ Among various oxide semiconductor photocatalysts, titanium dioxide, commonly called titania, has proven to be the most suitable for widespread applications, for its biological and chemical inertness, strong oxidation power, cost effectiveness and long-term stability against photo and chemical corrosion. ${ }^{5-8}$

The photocatalytic activity of semiconductors is due to the production of excited electrons in their conduction band along with the corresponding holes in their valence band by the absorption of photons with energy higher than the bandgap. The charge carriers can migrate to the surface, if they do not recombine, and react with pollutants adsorbed on the surface, decomposing them into innocuous substances.

Titania exists in two main crystallographic forms: anatase and rutile with band-gaps of $3.15 \mathrm{eV}$ and $3.05 \mathrm{eV}$, respectively; ${ }^{9}$ thus, ultraviolet (UV) irradiation is necessary in order to activate the photocatalyst material. Several attempts have been made to lower the band-gap energy of $\mathrm{TiO}_{2}$, in order to make the photocatalyst reactive under visible light $(\lambda>380 \mathrm{~nm})$ so to use the main part of the solar spectrum and even the poor illumination of interior-lighting. One approach was the doping of $\mathrm{TiO}_{2}$.

Metal-doped titania, the so-called "second-generation photocatalyst", has been widely studied for improved photocatalytic performance under visible light (VIS) irradiation. ${ }^{2,6,10-13}$ Otherwise, it is known that metal-ions behave as recombination centers, so that the electrons and holes

\footnotetext{
a) Author to whom correspondence should be addressed. Electronic mail: giuliana.impellizzeri@ct.infn.it
}

transfer to the interface is hindered. ${ }^{2}$ As a consequence, there is an optimum of doped metal ion concentration, above which the photocatalytic activity decreases due to the increase in electrons/holes recombination. ${ }^{2}$ We recently investigated the effect of $\mathrm{Fe}^{+}$ion-implantation on $100 \mathrm{~nm}$ $\mathrm{TiO}_{2}$ films, demonstrating that the iron implantation is able to lower the band-gap energy of titania, to a minimum value of $1.6 \mathrm{eV} .{ }^{14}$ The measured band-gap was associated with the presence of energy levels inside the energy band structure of the titania, due to implantation-induced defects in the films. The synthesized materials revealed a remarkable photocatalytic efficiency under VIS light irradiation $(80 \%$ higher than the one obtained for pure $\mathrm{TiO}_{2}$ films), without the help of any additional thermal treatment. ${ }^{14}$ We demonstrated that the photocatalytic activity in the degradation of organic compounds strongly depends on the amount of defects induced by the ion-implantation process. ${ }^{14}$

Non-metal doped $\mathrm{TiO}_{2}$ has been regarded as the "thirdgeneration photocatalyst". Various non-metal dopants have been widely studied for visible light photocatalytic activities. ${ }^{2,6}$ For example, Asahi and co-workers found that sputtered $\mathrm{N}$-doped $\mathrm{TiO}_{2}$ presented a higher photocatalytic activity in the degradation of methylene blue (MB) than pure $\mathrm{TiO}_{2}$, in the visible light region. ${ }^{15}$ A noticeable photocatalytic activity on the decomposition of $\mathrm{MB}$ in the visible region was demonstrated for C-doped $\mathrm{TiO}_{2}$, obtained from oxidation of TiC powders. ${ }^{16} \mathrm{C}$-doped $\mathrm{TiO}_{2}$, synthesized by flame pyrolysis of Ti sheets in a natural gas flame, displayed a lower band-gap than titania (2.32 versus $3.00 \mathrm{eV}) .{ }^{17}$ Even if there are several works in the literature focused on C-doped titania, ${ }^{17-20}$ and on doped $\mathrm{TiO}_{2}$ by the ion-implantation process, ${ }^{2,6,10,11,14}$ there is not, to our knowledge, any study on the effects of $\mathrm{C}$ doping by ion implantation. The advantage of the ion-implantation process is the outstanding control and repeatability of the implanted fluence and energy. 
The aim of this experimental research was to investigate the effect of $\mathrm{C}^{+}$implantation into $\mathrm{TiO}_{2}$ thin films $(\sim 110 \mathrm{~nm}$ in thickness) in terms of damage induced by the ionimplantation process into the polycrystalline matrix, optical properties of the synthesised materials and photocatalytic activity in the degradation of organic compounds in water under UV or VIS light irradiation.

\section{EXPERIMENTAL}

Titanium films were prepared by sputtering $\mathrm{Ti}$, at room temperature, on quartz substrates. In order to induce the complete oxidation of the titanium layers into $\mathrm{TiO}_{2}$, the samples were annealed at $600^{\circ} \mathrm{C}$ for $30 \mathrm{~min}$ in a conventional furnace under a controlled $\mathrm{O}_{2}$ flux. ${ }^{21}$ The thickness and the composition of the $\mathrm{TiO}_{2}$ films were investigated by Rutherford Backscattering Spectrometry (RBS), with a $3.5 \mathrm{MeV}$ HVEE Singletron accelerator, using a $2 \mathrm{MeV} \mathrm{He}{ }^{+}$beam with $165^{\circ}$ scattering angle. The samples were then implanted with $\mathrm{C}^{+}$ ions at $20 \mathrm{keV}$, with a fluence of $1 \times 10^{15} \mathrm{~cm}^{-2}$. During implantation, the average current density was $\sim 0.02 \mu \mathrm{A} / \mathrm{cm}^{2}$, and the substrates were held at room temperature. Afterwards some samples were annealed at 450,550 , or $650^{\circ} \mathrm{C}$ for $2 \mathrm{~h}$ in an Ar atmosphere.

Secondary Ion Mass Spectrometry (SIMS) was used to obtain the chemical profiles of carbon. The SIMS analyses were performed with a CAMECA IMS- $4 f$ instrument, using a $14.5 \mathrm{keV} \mathrm{Cs}{ }^{+}$sputtering beam and collecting secondary negative ions, while flooding the sample with an electron gun in order to neutralize charging and maintain a fixed and stable surface potential. Depth scales were calibrated by evaluating the erosion rates in $\mathrm{TiO}_{2}$ and $\mathrm{SiO}_{2}$ (i.e., the underlying quartz) through a dedicated procedure based on measurements of the crater depths with a profilometer after sputtering in both materials. The overall accuracy was $10 \%$.

The structure of the films was studied by X-Ray Diffraction (XRD) analyses with a Bruker D-500 diffractometer at several angles of incidence, from 0.8 to $1.0^{\circ}$, and $\Theta$ $2 \Theta$ from 20 to $60^{\circ}$. The XRD spectra were analyzed by the Bruker software suite, including ICSD structure database. The vibrational and electronic properties of the films were analyzed through their Raman and photoluminescence responses, respectively, using an XploRA Horiba JobinYvon spectrometer.

The UV-VIS optical characterization was obtained by extracting both the normal transmittance (T) and the $20^{\circ}$ reflectance (R) spectra in the $200-800 \mathrm{~nm}$ wavelength range, by using a Varian Cary 500 double beam scanning UV/VIS/ NIR spectrophotometer.

The photocatalytic activity of the investigated materials was evaluated by the degradation of MB, following the ISO protocol. ${ }^{22}$ As a first step, the samples $(0.8 \mathrm{~cm} \times 0.8 \mathrm{~cm}$ in size) were irradiated by an UV lamp for $50 \mathrm{~min}$ in order to remove the hydrocarbons localized on the sample surface. ${ }^{23}$ Then, the samples were immersed in a $2 \mathrm{ml}$ solution containing $\mathrm{MB}$ and de-ionized water, with a starting concentration of MB of $1.3 \times 10^{-5} \mathrm{M}$. The mixture was irradiated by an UV lamp (350-400 nm wavelength range) with a power of $8 \mathrm{~W}$, or by a VIS lamp (390-535 nm wavelength range) with a power of $12 \mathrm{~W}$, for a total time of $210 \mathrm{~min}$. Both the UV and VIS lamps used for the irradiation do not emit in the region of absorption of the MB, as a consequence the measured degradation of the MB can be only ascribed to the presence of the photocatalysts. Every $30 \mathrm{~min}$ of irradiation the absorption of the solutions was measured with a UV-VIS spectrophotometer (Perkin-Elmer Lambda 35) in a wavelength range between 500 and $800 \mathrm{~nm}$. The degradation of MB was evaluated by the absorbance of the MB peak at $664 \mathrm{~nm}$, according to the Lambert-Beer law: $A=\varepsilon \times l \times C$, where $A$ is the absorbance of the solution at $664 \mathrm{~nm}, \varepsilon$ is the extinction molar coefficient, $l$ is the width of the cuvette, and $C$ is the concentration of the MB. ${ }^{24}$ The decomposition of the MB in the absence of any photocatalyst material was also checked as a reference. Control experiments in the dark were conducted, providing evidence of any contribution of the adsorption of the MB at the sample surface.

\section{RESULTS AND DISCUSSION}

The RBS analyses (not shown) of the films obtained after the oxidation process of the sputtered Ti films gave as a result the stoichiometry of the $\mathrm{TiO}_{2}$ and a thickness of $\sim 110 \mathrm{~nm}$ (in detail, $104 \mathrm{~nm}$ considering the density of the rutile phase, $114 \mathrm{~nm}$ considering the density of the anatase phase $^{25}$ ).

Figure 1 reports the simulated distribution profile of carbon ions implanted in $\mathrm{TiO}_{2}$ at $20 \mathrm{keV}$ (dotted line, right axis). ${ }^{26}$ The energy was obtained by the SRIM code ${ }^{26}$ so that the implanted profile was fully contained in the $\mathrm{TiO}_{2}$ layers (C projected range $\sim 50 \mathrm{~nm}$ ). On the left axis the $\mathrm{C}$ profiles (in counts/s), obtained by SIMS analyses for the asimplanted (continuous line) and $650{ }^{\circ} \mathrm{C}$ annealed sample (dashed line), are reported. The layer thickness resulted to be $110 \pm 10 \mathrm{~nm}$ which, if compared with the $\mathrm{TiO}_{2}$ areal density estimated by RBS gives a $\mathrm{TiO}_{2}$ molecular density of $9.0 \times 10^{22}$ atoms $/ \mathrm{cm}^{3}$. This density is in agreement, within $6 \%$, with the density of $\mathrm{TiO}_{2}$ reported in literature ${ }^{25}$ and used by the SRIM code ${ }^{26}$ thus confirming there is no significant porosity in the layer. The $\mathrm{C}$ profile clearly shows a peculiar, outside the experimental errors, redistribution just

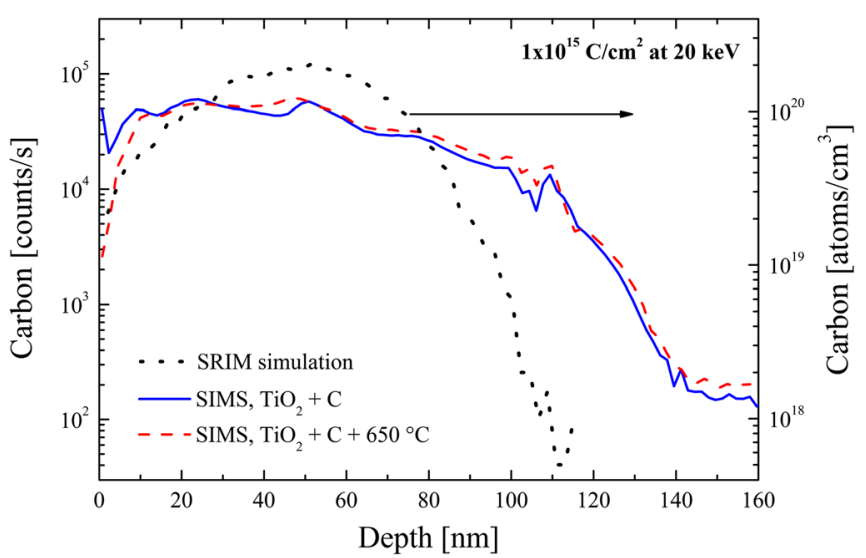

FIG. 1. Carbon chemical profiles just after the implantation $\left(1 \times 10^{15} \mathrm{~cm}^{-2}\right.$ at $20 \mathrm{keV}$, straight line) and after annealing at $650^{\circ} \mathrm{C}$ for $2 \mathrm{~h}$ (dashed line). The simulation ${ }^{26}$ of the implanted profile is also reported on the right vertical axis (dotted line). 


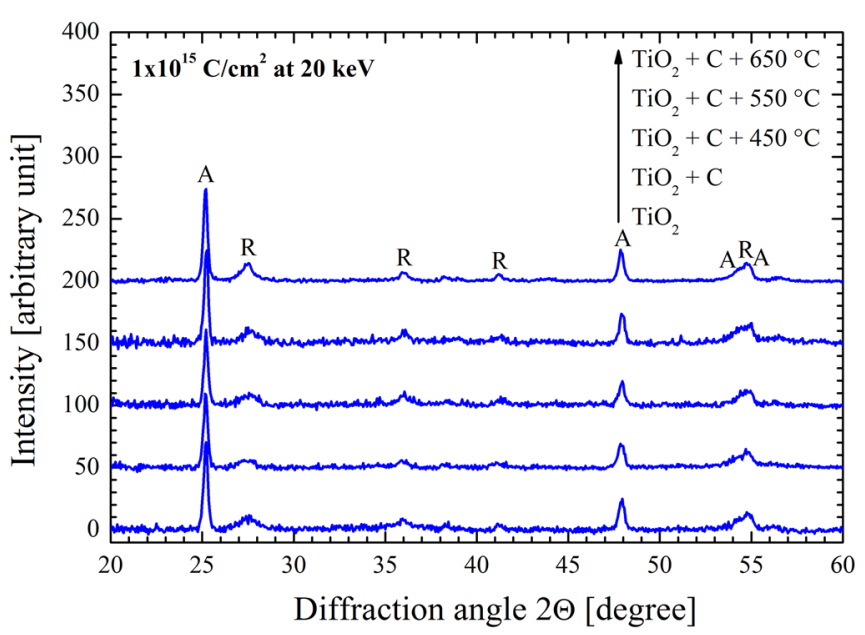

FIG. 2. XRD patterns of pure $\mathrm{TiO}_{2}$ film, C-implanted $\left(1 \times 10^{15} \mathrm{~cm}^{-2}\right.$ at $20 \mathrm{keV}$ ) and after the thermal treatments. "A" refers to the anatase phase, " $R$ " to the rutile phase.

during the implant, indicating that $\mathrm{C}$ migration takes place at room temperature upon implantation, while non $\mathrm{C}$ loss is observed up to the temperature of $650{ }^{\circ} \mathrm{C}$ (i.e., the highest temperature used for this work).

The XRD patterns of the starting $\mathrm{TiO}_{2}$ film, asimplanted and after the thermal treatments are shown in Fig. 2. The XRD analyses only detected the presence of anatase and rutile crystalline phases (marked by " $A$ " and " $R$ ", respectively, in the figure). Un-doped films were found to crystallize at $600{ }^{\circ} \mathrm{C}$ into anatase and rutile phases. The ion implantation induced a slight reduction of the peak intensities, which can be ascribed to a weak damaging process, typical of ion-implantation for this low fluence. ${ }^{27}$ The thermal treatments induced a damage recover, as expected.

The low frequency Raman spectra (below $700 \mathrm{~cm}^{-1}$ ) for the $\mathrm{TiO}_{2}$ film, as-implanted and after the thermal treatments, are reported in Fig. 3. The analyses were performed with an excitation wavelength of $532 \mathrm{~nm}$ (i.e., $2.33 \mathrm{eV}$ ). The strongest Raman lines at $\sim 150,400,517$, and $648 \mathrm{~cm}^{-1}$ can be assigned as $\mathrm{E}_{\mathrm{g}}, \mathrm{B}_{1 \mathrm{~g}}, \mathrm{~A}_{1 \mathrm{~g}}$, and $\mathrm{E}_{\mathrm{g}}$ modes of the anatase

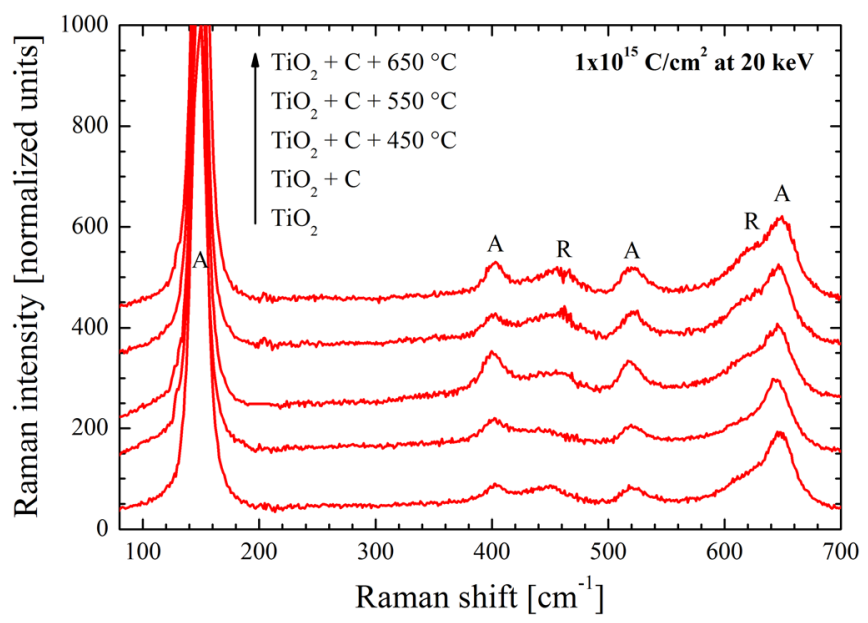

FIG. 3. Raman spectra for the $\mathrm{TiO}_{2}$ film, C-implanted $\left(1 \times 10^{15} \mathrm{~cm}^{-2}\right.$ at $20 \mathrm{keV}$ ) and after the thermal treatments. "A" indicates the modes relative to the anatase phase, "R" the modes relative to the rutile phase. The excitation wavelength was $532 \mathrm{~nm}$. phase, ${ }^{28}$ respectively (they are marked by " $\mathrm{A}$ " in the figure). The analyses also reveled two weak peaks near 462 and $628 \mathrm{~cm}^{-1}$, that correspond to $\mathrm{E}_{\mathrm{g}}$ and $\mathrm{A}_{1 \mathrm{~g}}$ modes of the rutile phase, ${ }^{28}$ respectively (they are marked by " $R$ " in the figure). The signal originating from the quartz substrate was subtracted, the intensities were normalized to the highest anatase mode (near $150 \mathrm{~cm}^{-1}$ ) and the spectra were up-shifted, for an easier comparison. We estimated that the ratio between the amount of anatase phase versus the rutile one, in the $\mathrm{TiO}_{2}$ starting layers was $\sim 2{ }^{29}$ In addition, the Raman spectra of the titania layers were not generally modified by the ion implantation and post-annealing processes: the crystalline quality and composition are rather well preserved during these processes and totally recovered after annealing at the higher temperature of $650{ }^{\circ} \mathrm{C}$.

Figure 4 reports the high frequency Raman spectra (Stokes shift above $1100 \mathrm{~cm}^{-1}$, i.e., absolute photon energy below $2.2 \mathrm{eV}$ ). These spectra were also arbitrarily shifted for a better comparison. In the annealed samples, the $D$ and $G$ features (corresponding to a Raman shift of 1450 and $1590 \mathrm{~cm}^{-1}$, respectively) are characteristic signatures of "disorder" and graphite $\mathrm{C}=\mathrm{C}$ bands. Their presence testifies to some clustering of $\mathrm{C}$ atoms. At the same time in these samples a broad "luminescence" band is observed around $4000 \mathrm{~cm}^{-1}$. This is indeed a luminescence band because its absolute position $(1.83 \mathrm{eV}$ or $676 \mathrm{~nm})$ remains unchanged when the laser excitation wavelength is changed from 532 to $638 \mathrm{~nm}$ (not shown). We tentatively attribute it to in-gap levels created by the implantation process that act as recombination centers upon annealing.

The optical properties of the investigated samples were analysed by UV-VIS optical characterization. Figure 5 reports the absorbance for pure $\mathrm{TiO}_{2}$ film, C-implanted and $\mathrm{C}$-implanted after the thermal treatments. The absorbance (A) was obtained by the transmittance (T) and reflectance (R) measured spectra, in accordance with the following equation: $\mathrm{A} \%=100-\mathrm{T} \%-\mathrm{R} \%$. The pure titania film shows the typical optical absorption in the UV part of the spectrum, for wavelengths shorter than $\sim 390 \mathrm{~nm}$ (line plus closed circles in Fig. 5). Otherwise, the C-doped films exhibit an

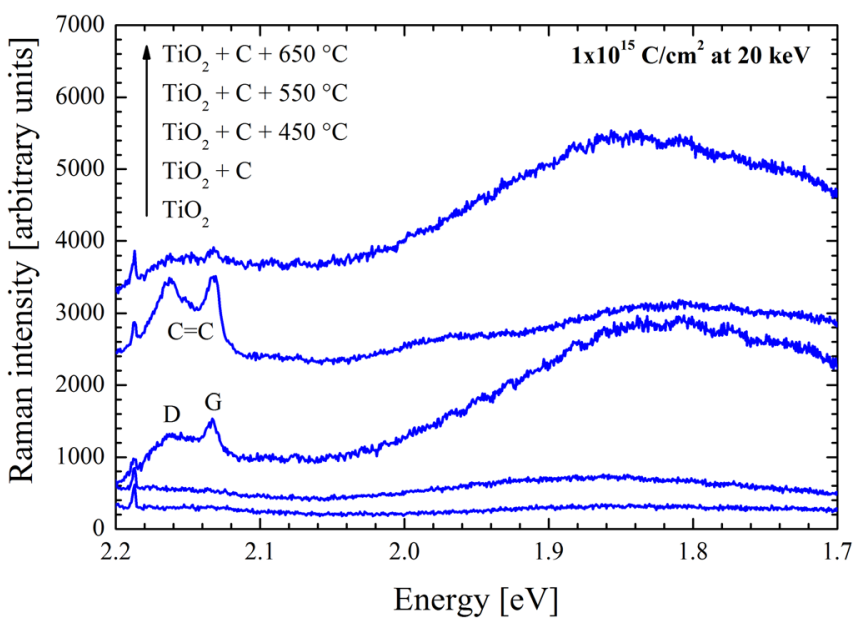

FIG. 4. Luminescence spectra of the same samples as in Fig. 3. The $\mathrm{C}=\mathrm{C}$ indication refers to Raman scattering by disordered graphitic carbon modes. 


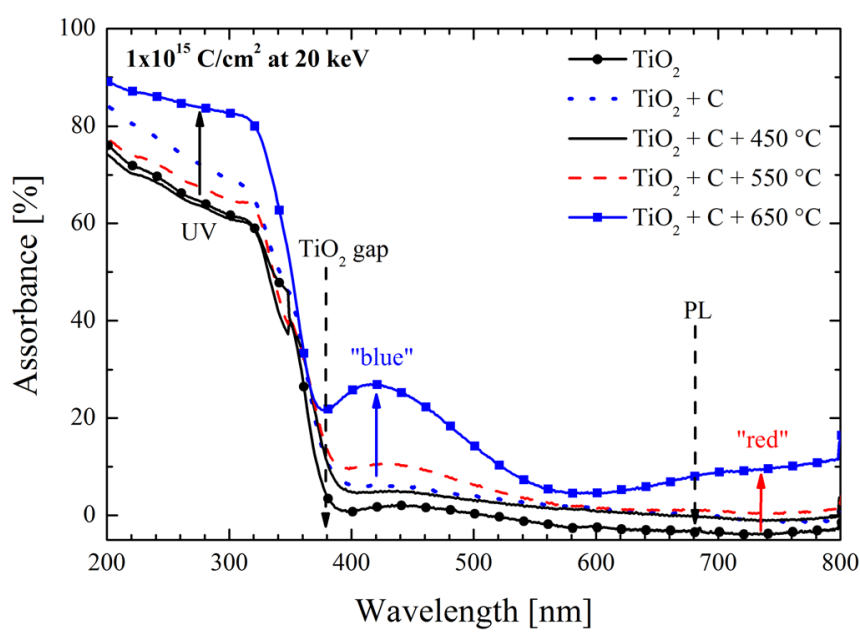

FIG. 5. Absorbance spectra of the pure $\mathrm{TiO}_{2}$ film, C-implanted $\left(1 \times 10^{15} \mathrm{~cm}^{-2}\right.$ at $\left.20 \mathrm{keV}\right)$ and after the thermal treatments.

absorbance increase in the UV range (below $350 \mathrm{~nm}$ ) and a new absorption band in the VIS part of the spectrum, in the form of a bump around $430 \mathrm{~nm}$ ("blue" range). In detail, the as-implanted samples show in this range an absorbance of $\sim 6 \%$ (dotted line in Fig. 5). With thermal treatments higher than $450{ }^{\circ} \mathrm{C}$, the absorption band increases with the temperature: $\sim 11 \%$ for the temperature of $550{ }^{\circ} \mathrm{C}, \sim 27 \%$ for $650{ }^{\circ} \mathrm{C}$ (dashed line and line plus closed squares, respectively, in Fig. 5). Moreover, these measurements indicate the formation of a large absorption tail above $650 \mathrm{~nm}$ ("red" range) which may be correlated with the luminescence spectra (see Fig. 4) and the presence of deep levels in the titania gap.

Optical spectra were analysed by the Tauc model, which describes the light absorption process in amorphous semiconductors. ${ }^{30}$ For indirect transitions (that is the case of $\mathrm{TiO}_{2}$ ) the Tauc law can be written as follows: ${ }^{31}$

$$
\alpha=\frac{B}{h \nu}\left(h \nu-E_{g}\right)^{2},
$$

where $B$ is the Tauc constant, ${ }^{32} h \nu$ is the incoming photon energy, $E_{g}$ is the optical band-gap of the material, $\alpha$ is the absorption coefficient that were extracted from the transmittance $(\mathrm{T})$, and reflectance $(\mathrm{R})$ measurements performed on each sample by using the following equation:

$$
\alpha=\frac{1}{d} \ln \frac{T_{Q}\left(1-R_{S}\right)}{T_{S}},
$$

where $d$ is the thickness of the film; the subscripts Q and S refer to the quartz or the sample, respectively. Another condition of the Tauc law is that $\alpha$ is higher than $1 \times 10^{4} \mathrm{~cm}^{-1} \cdot{ }^{30} \mathrm{By}$ plotting $(\alpha \times h \nu)^{1 / 2}$ versus $h \nu$ (i.e., Tauc plot) and using a linear fit, $E_{g}$ can be extracted for all the samples $\left(E_{g}\right.$ is the intercept of the linear fit with the abscissa axis). The Tauc plot of the pure $\mathrm{TiO}_{2}$ film (not shown) gave an energy gap of $3.3 \mathrm{eV}$ $(\sim 370 \mathrm{~nm})$. Assuming an error of $\sim 10 \%$ in the determination of the band-gap, the value of $3.3 \mathrm{eV}$ is in good agreement with the values reported in the literature for bulk anatase and rutile $\mathrm{TiO}_{2}(3.15 \mathrm{eV}$ and $3.05 \mathrm{eV}$ for anatase and rutile phase, respectively). ${ }^{9}$ In Fig. 6, the Tauc plot of the $\mathrm{TiO}_{2}$ film implanted with carbon and annealed at $650{ }^{\circ} \mathrm{C}$ is reported. The linear fit

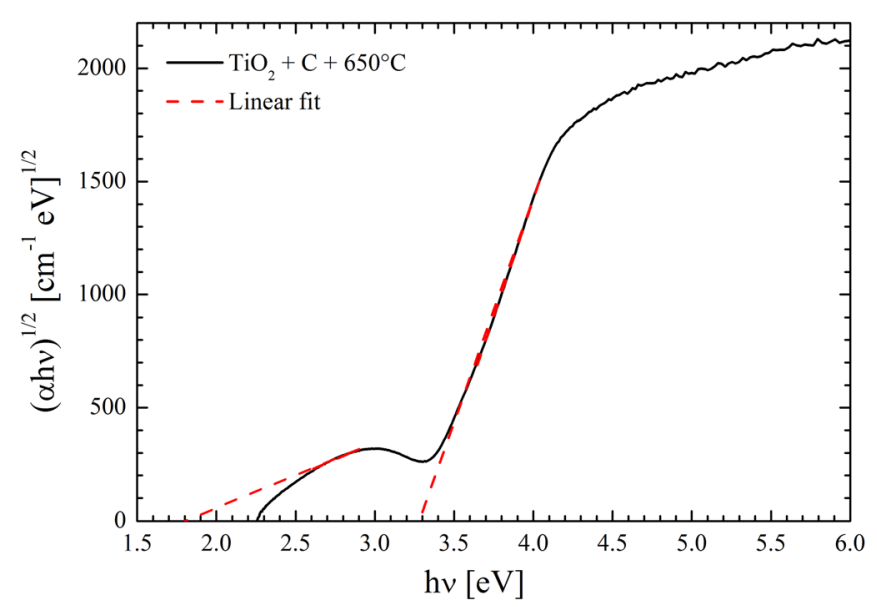

FIG. 6. Tauc plot for the $\mathrm{TiO}_{2}$ film implanted with $\mathrm{C}^{+} 1 \times 10^{15} \mathrm{~cm}^{-2}$ at $20 \mathrm{keV}$ and annealed at $650^{\circ} \mathrm{C}$ (continuous line), together with the linear fit (dotted line).

(dotted lines in Fig. 6) reveal the presence of two optical bandgaps: one at $3.3 \mathrm{eV}$, that can be assigned to the titania, and another one at $1.8 \mathrm{eV}(\sim 680 \mathrm{~nm})$, which can be correlated to the carbon doping. This latter value is equal within the error to the value of $1.83 \mathrm{eV}$ determined above by the luminescence measurements. Therefore, the significant absorption obtained in the VIS part of the spectra probably originates from in-gap levels created by the implantation process.

$\mathrm{MB}$ degradation measurements were performed in order to investigate the photocatalytic activity of the C-doped films in the degradation of organic compounds in water under UV and VIS irradiation. According to the Langmuir-Hinshelwood model, the photocatalytic reaction rate, $k$, of water contaminants is given by the following reaction:

$$
\ln \left(\frac{C}{C_{0}}\right)=-k t,
$$

where $C$ is the concentration of organic species, $C_{O}$ is the starting concentration of organic species, and $t$ is the time. ${ }^{3} \mathrm{We}$ report in Fig. 7 the photodegradation rate of the MB, normalized to the value obtained for the MB decomposition in the absence of any catalyst materials, for the different samples, both under UV (Fig. 7(a)) and VIS light irradiation (Fig. 7(b)). In the abscissa axis, $M B$ indicates the $\mathrm{MB}$ decomposition in the absence of any catalyst, normalized to 1 (i.e., $k / k_{M B}$ ); $\mathrm{TiO}_{2}$ refers to the $\mathrm{MB}$ decomposition due to the pure $\mathrm{TiO}_{2}$ film; as-implanted indicates the $\mathrm{MB}$ decomposition due to the C-doped $\mathrm{TiO}_{2}$ films; $450^{\circ} \mathrm{C}$ refers to the $\mathrm{MB}$ decomposition due to the $\mathrm{TiO}_{2}$ films implanted with $\mathrm{C}$ and annealed at $450{ }^{\circ} \mathrm{C}$, etc. The best response in terms of photodegradation of $\mathrm{MB}$ was displayed by the $\mathrm{C}$-implanted $\mathrm{TiO}_{2}$ films, under both UV and VIS irradiation (Figs. 7(a) and 7(b), respectively). The results showed an increase of $\sim 40 \%$ for the UV irradiation and $\sim 25 \%$ for the VIS ("blue" range) irradiation with respect to the pure titania films. The photocatalytic efficiency decreased, with respect to the as-implanted layers, with the annealing. In addition, we can observe that the photocatalytic trend is almost similar under both the UV and VIS irradiation. In particular, the photocatalytic efficiency under VIS irradiation is higher in the as-implanted layer than in pure and 

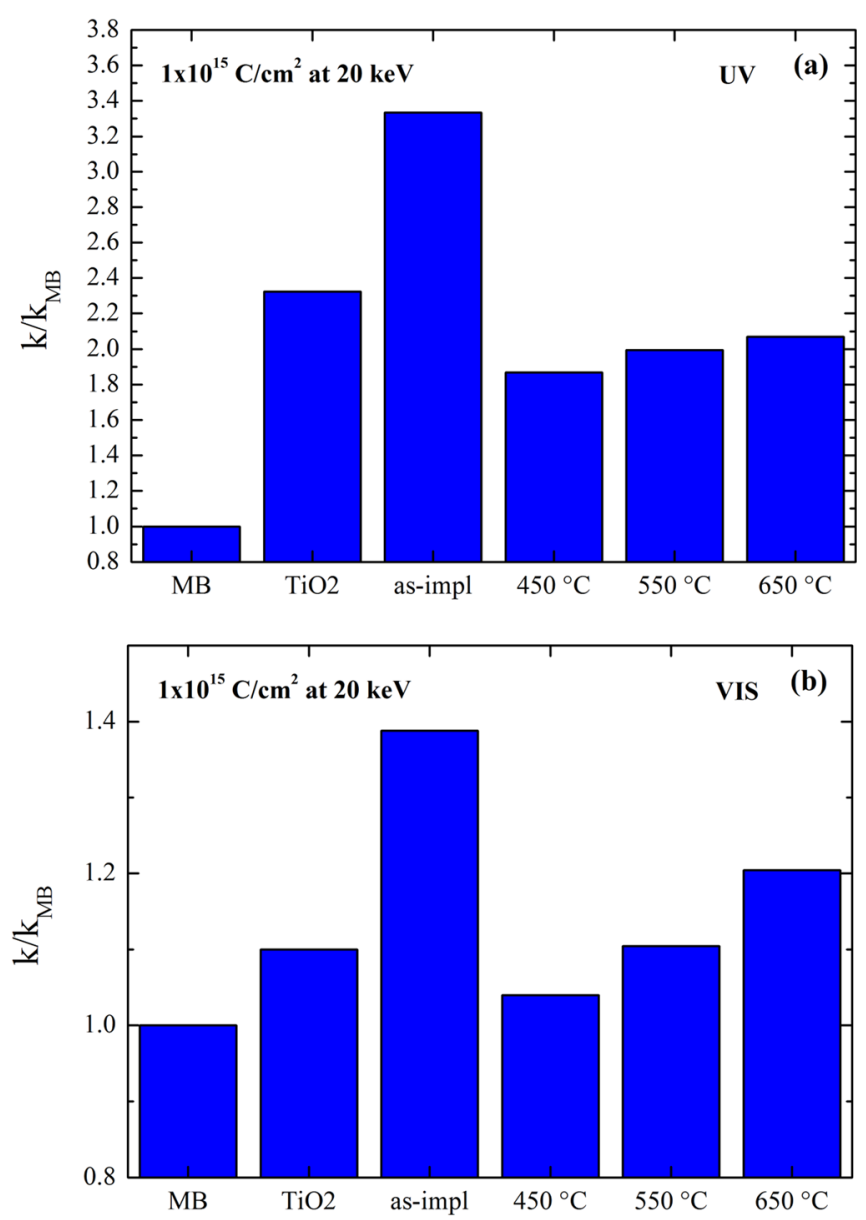

FIG. 7. Photocatalytic rate of MB, normalized to the value obtained for the $\mathrm{MB}$ in the absence of the photocatalyst, for the C-doped films $\left(1 \times 10^{15} \mathrm{~cm}^{-2}\right)$ under the UV (a) and VIS light irradiation (b).

annealed $\mathrm{TiO}_{2}$. This drop of the photocatalytic efficiency as a function of the thermal treatments can be correlated to the $\mathrm{C}=\mathrm{C}$ bands observed by the Raman analyses, which appear upon annealing. Therefore, we can speculate that the occurrence of carbon clustering works against the photodegradation of organic pollutants. The above results point to the following scenario: dynamic annealing of point defects and $\mathrm{C}$ migration phenomena, taking place during $\mathrm{C}^{+}$ion implantation, are responsible for an effective carbon incorporation into $\mathrm{TiO}_{2}$ with little accumulated lattice damage. This damage induce the reduction of the $\mathrm{TiO}_{2}$ energy gap, through the formation of ingap levels, that increase the photocatalytic efficiency of the material. Further annealing induces a carbon clustering which has a detrimental effect on the photocatalytic efficiency, since carbon clusters play as efficient recombination centers for charge carriers.

These experimental results clearly demonstrate that a small band-gap $(\sim 1.8 \mathrm{eV})$ can be achieved by $\mathrm{C}^{+}$doping of $\mathrm{TiO}_{2}$ films, and a significant photocatalytic efficiency can be obtained under VIS light irradiation, without the help of any thermal treatments.

\section{CONCLUSIONS}

In conclusion, we presented a detailed study concerning the effect of $\mathrm{C}^{+}$ion-implantation $\left(1 \times 10^{15} \mathrm{~cm}^{-2}\right.$ at $\left.20 \mathrm{keV}\right)$ on a thin $\mathrm{TiO}_{2}$ pure film (110 nm thick), eventually annealed up to $650{ }^{\circ} \mathrm{C}$, so as to realize an efficient third-generation photocatalyst. The reported results confirmed that ion implantation is able to modify the $\mathrm{TiO}_{2}$ pure film, lowering its band-gap energy to a minimum value of $\sim 1.8 \mathrm{eV}$, so as to absorb visible light. The synthesized materials revealed a substantial photodegradation efficiency under UV and VIS light irradiation: $\sim 40 \%$ and $\sim 25 \%$ higher than that obtained for pure titania films, without the help of any additional thermal treatment.

The synthesized materials can be attractive for a wide range of applications for water purification, air purification but also for the production of hydrogen fuel by water splitting.

\section{ACKNOWLEDGMENTS}

The authors wish to thank S. Tatì (CNR-IMM MATIS) and S. Di Franco (CNR-IMM) for their expert technical assistance. This research has been supported by the FP7 European Project WATER (Grant Agreement n. 316082).

${ }^{1}$ M. A. Shannon, P. W. Bohn, M. Elimelech, J. G. Georgiadis, B. J. Marinas, and A. M. Mayes, Nature 452, 301 (2008).

${ }^{2}$ S. Malato, P. Fernàndez-Ibáñez, M. I. Maldonado, J. Blanco, and W. Gernjak, Catal. Today 147, 1 (2009).

${ }^{3}$ M. N. Chong, B. Jin, C. W. K. Chow, and C. Saint, Water Res. 44, 2997 (2010).

${ }^{4}$ W. Y. Teoh, J. A. Scott, and R. Amal, J. Phys. Chem. Lett. 3, 629 (2012).

${ }^{5}$ A. Fujishima, T. N. Rao, and D. A. Tryk, J. Photochem. Photobiol. C: Photochem. Rev. 1, 1 (2000).

${ }^{6}$ X. Chen and S. S. Mao, Chem. Rev. 107, 2891 (2007).

${ }^{7}$ V. Scuderi, G. Impellizzeri, L. Romano, M. Scuderi, G. Nicotra, K. Bergum, A. Irrera, B. G. Svensson, and V. Privitera, Nanoscale Res. Lett. 9, 458 (2014).

${ }^{8}$ V. Scuderi, G. Impellizzeri, L. Romano, M. Scuderi, M. V. Brundo, K. Bergum, M. Zimbone, R. Sanz, M. A. Buccheri, F. Simone, G. Nicotra, B. G. Svensson, M. G. Grimaldi, and V. Privitera, Nanoscale 6, 11189 (2014).

${ }^{9}$ A. Bendavid, P. J. Martin, A. Jamting, and H. Takikawa, Thin Solid Films 355-356, 6 (1999).

${ }^{10}$ M. Anpo and M. Takeuchi, J. Catal. 216, 505 (2003).

${ }^{11}$ H. Yamashita, M. Harada, J. Misaka, M. Takeuchi, B. Neppolian, and M. Anpo, Catal. Today 84, 191 (2003).

${ }^{12}$ S. Zhang, Y. Chen, Y. Yu, H. Wu, S. Wang, B. Zhu, W. Huang, and S. Wu, J. Nanopart. Res. 10, 871 (2008).

${ }^{13}$ J. Yu, Q. Xiang, and M. Zhou, Appl. Catal. B: Environ. 90, 595 (2009).

${ }^{14}$ G. Impellizzeri, V. Scuderi, L. Romano, P. M. Sberna, E. Arcadipane, R. Sanz, M. Scuderi, G. Nicotra, M. Bayle, R. Carles, F. Simone, and V. Privitera, J. Appl. Phys. 116, 173507 (2014).

${ }^{15}$ R. Asahi, T. Morikawa, T. Ohwaki, K. Aoki, and Y. Taga, Science 293, 269 (2001).

${ }^{16}$ Y. Choi, T. Umebayashi, and M. Yoshikawa, J. Mater. Sci. 39, 1837 (2004).

${ }^{17}$ S. U. M. Khan, M. Al-Shahry, and W. B. Ingler, Jr., Science 297, 2243 (2002).

${ }^{18}$ E. Barborini, A. M. Conti, I. Kholmanov, P. Piseri, A. Podestà, P. Milani, C. Cepek, O. Sakho, R. Macovez, and M. Sancrotti, Adv. Mater. 17, 1842 (2005).

${ }^{19}$ J. H. Park, S. Kim, and A. J. Bard, Nano Lett. 6, 24 (2006).

${ }^{20}$ R. Hahn, A. Ghicov, J. Salonen, V.-P. Lehto, and P. Schmuki, Nanotechnology 18, 105604 (2007).

${ }^{21}$ D. Velten, V. Biehl, F. Aubertin, B. Valeske, W. Possart, and J. Breme, J. Biomed. Mater. Res. 59, 18 (2002).

${ }^{22} \mathrm{H}$. Zollinger, Color Chemistry, Synthesis, Properties and Applications of Organic Dyes and Pigments (VCH, Weinheim, Germany, 1991).

${ }^{23}$ R. Wang, K. Hashimoto, A. Fujishima, M. Chikuni, E. Kojima, A. Kitamura, M. Shimohigoshi, and T. Watanabe, Nature 388, 431 (1997). 
${ }^{24}$ A. D. McNaught and A. Wilkinson, "Compendium of chemical terminology," in The Gold Book, 2nd ed. (Blackwell Scientific Publications, Oxford, 1997).

${ }^{25}$ D. A. H. Hanaor and C. C. Sorrell, J. Mater. Sci. 46, 855 (2011).

${ }^{26}$ J. F. Ziegler, J. P. Biersack, and U. Littmark, The Stopping and Range of Ions in Solids (Pergamon, New York, 1984), Vol. 1, http://www.srim.org.

${ }^{27}$ E. Rimini, Ion Implantation: Basics to Device Fabrication (Kluwer Academic Publishers, Boston, 1995).
${ }^{28}$ W. F. Zhang, Y. L. He, M. S. Zhang, Z. Yin, and Q. Chen, J. Phys. D: Appl. Phys. 33, 912 (2000).

${ }^{29}$ J. Zhang, M. Li, Z. Feng, J. Chen, and C. Li, J. Phys. Chem. B 110, 927 (2006).

${ }^{30}$ J. Tauc, Amorphous and Liquid Semiconductors (Plenum, New York, 1974), p. 175.

${ }^{31}$ J. Pascual, J. Camassel, and H. Mathieu, Phys. Rev. Lett. 39, 1490 (1977).

${ }^{32}$ S. Knief and W. von Niessen, Phys. Rev. B 59, 12940 (1999). 